Researc Paper

\title{
Effects of Memantine on the Spontaneous Firing Frequency of Hippocampal CA1 Pyramidal Neurons in Intact and Alzheimer Rat Model: An Electrophysiological Study
}

\author{
Nastaran Zamani $^{1 *}$ (D), Ahmad Ali Moazedi ${ }^{2,3}$ (D), Mohamad Reza Afarinesh Khaki ${ }^{4}$ (D), Mehdi Pourmehdi Boroujeni ${ }^{5}$ (D) \\ 1. Department of Biology, School of Science, Payame Noor University, Tehran, Iran. \\ 2. Department of Biology, School of Science, Shahid Chamran University of Ahvaz, Ahvaz, Iran. \\ 3. Stem Cell and Transgenic Technology Research Center, Shahid Chamran University of Ahvaz, Ahvaz, Iran. \\ 4. Kerman Cognitive Research Center, Kerman Neuroscience Research Center, Institute of Neuropharmachology, Kerman University of Medical \\ Sciences, Kerman, Iran. \\ 5. Department of Food Hygiene, School of Veterinary Medicine, Shahid Chamran University of Ahvaz, Ahvaz, Iran.
}

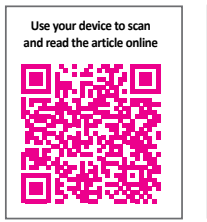

Citation Zamani, N., Moazedi, A. A., Afarinesh Khaki, M. R., and Pourmehdi Boroujeni, M. (2022). Effects of Memantine on the Spontaneous Firing Frequency of Hippocampal CA1 Pyramidal Neurons in Intact and Alzheimer Rat Model: An Electrophysiological Study. Basic and Clinical Neuroscience, 13(5), 661-674. http://dx.doi.org/10.32598/bcn.2021.1970.1

dol'http://dx.doi.org/10.32598/bcn.2021.1970.1

\section{(i) (5)}

Article info:

Received: 05 Aug 2019

First Revision: 05 Feb 2020

Accepted: 19 Apr 2020

Available Online: 01 Sep 2022
Keywords:

Alzheimer disease,

Acetylcholine, Memantine, Hippocampal neurons, Singleunit recording

\section{ABS T RA C T}

Introduction: Memantine (MEM) is a noncompetitive N-methyl-D-aspartate receptor (NMDAR) antagonist clinically used for the treatment of Alzheimer disease (AD) in mild to severe conditions. The present study was conducted to investigate the effects of memantine on the spontaneous firing frequency of CA1 pyramidal neurons in rats caused by an electrical lesion of Nucleus Basalis Magnocellularis (NBM). Then, this model of $\mathrm{AD}$ rats was compared with the intact adult male rats.

Methods: In this study, adult male rats were divided into two groups. Group I (lesion of $\mathrm{NBM}, \mathrm{n}=53$ ) includes the following subgroups: lesion+saline, sham+saline, lesion+MEM 5 $\mathrm{mg} / \mathrm{kg}$, lesion+MEM $10 \mathrm{mg} / \mathrm{kg}$, and lesion+MEM 20mg $\mathrm{kg}$. Group II (intact, $\mathrm{n}=48$ ) includes the following subgroups: intact+saline, intact+MEM $3 \mathrm{mg} / \mathrm{kg}$, intact+MEM $5 \mathrm{mg} / \mathrm{kg}$, and intact + MEM $10 \mathrm{mg} / \mathrm{kg}$. Extracellular single-unit recording (15 min baseline+105 min after MEM or saline) was performed under urethane-anesthetized rats.

Results: The results showed that the mean frequency of CA1 pyramidal neurons after saline in the lesion + saline $(\mathrm{P}<0.001)$ group significantly decreases compared with the intact + saline and sham + saline groups. In addition, after saline and memantine, the mean frequency of CA1 pyramidal neurons in the lesion+MEM $10 \mathrm{mg} / \mathrm{kg}(\mathrm{P}<0.01)$ and lesion+MEM $20 \mathrm{mg}$ / $\mathrm{kg}(\mathrm{P}<0.001)$ groups significantly increased compared with the lesion + saline group. Also, the mean frequencies of CA1 pyramidal neurons in the intact+MEM $10 \mathrm{mg} / \mathrm{kg}(\mathrm{P}<0.001)$ group significantly decreased compared with the intact+saline group.

Conclusion: Results showed that memantine increases the electrical activity of CA1 pyramidal neurons in a rat model of $\mathrm{AD}$. Furthermore, in the intact adult male rats, the low-dose memantine, contrary to high dose, does not decrease the electrical activity of CA1 pyramidal neurons.

\footnotetext{
* Corresponding Author:

Nastaran Zamani, PhD.

Address: Department of Biology, School of Science, Payame Noor University, Tehran, Iran.

Tel: +98 (81) 32546721

E-mail: na_zamani2000@pnu.ac.ir
} 


\section{Highlights}

- Alzheimer disease (AD) model was induced by creating bilateral lesions in the nucleus basalis magnocellularis (NBM) using the electrical method.

- The spontaneous firing frequency of CA1 pyramidal neurons of the hippocampus in the intact and Alzheimer rat model was investigated.

- Decreasing the spontaneous firing frequency of CA1 pyramidal neurons destructed NBM.

- Memantine administration improved the activity of pyramidal neurons in a rat model of AD.

- Low-dose memantine, contrary to its high dose, did not decrease the electrical activity of CA1 pyramidal neurons in intact adult male rats.

\section{Plain Language Summary}

Alzheimer disease (AD) is a progressive neurodegenerative disorder and the most common cause of dementia. One of the features of this disease is the reduction of cholinergic neurons in the basal forebrain. Basal forebrain cholinergic cell groups in rodents are known as the Nucleus Basalis Magnocellularis (NBM). Memantine increases the signal-to-noise ratio and affects the change in the balance between excitation and inhibition away from inhibition in the prefrontal cortex. In the present study with bilateral lesions of NBM, a model of animal AD was created that reduced the electrical activity of CA1 pyramidal neurons, while injection of memantine improved the activity of these neurons. In addition, in intact adult male rats, low-dose memantine, contrary to its high dose, did not decrease the electrical activity of CA1 pyramidal neurons.

\section{Introduction}

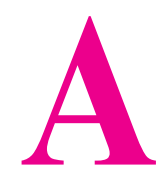

lzheimer disease $(\mathrm{AD})$ is a progressive neurodegenerative disorder and the most common cause of dementia, which imposes immense suffering on patients and their families (Du, Wang \& Geng, 2018). The extracellular accumulation of amyloid beta $(A \beta)$ peptides in the cerebral cortex and the hippocampus are the pathological feature of $\mathrm{AD}$, which indicates that abnormal $A \beta$ processing plays an important role in the progression of the disease. Another feature of this disease is the reduced cholinergic neurons in the basal forebrain (Castaneda et al., 2015).

Basal forebrain cholinergic cell groups in rodents are known as the Nucleus Basalis Magnocellularis (NBM), whose branches extend to the dorsolateral surfaces of the cortical mantle, prefrontal cortex, and basolateral complex of the amygdala (Knox, 2016; Nyakas et al., 2011). It has been shown that NBM lesions impair cognition (Llorente-Ovejero et al., 2017), lower spatial learning (Hoveizi et al., 2018), and reduce Choline Acetyltransferase (ChAT) in the frontal cortex (Panocka et al., 1995). Also, ibotenic acid-induced NBM lesions decrease basal synaptic responsiveness, paired-pulse re- sponses, and long-term potentiation (LTP) in the dentate gyrus (DG) of rats. It indicates that although NBM does not send direct cholinergic projections to the hippocampus, its lesion affects both short-term and long-term neural plasticity in the dentate gyrus (Hosseini et al., 2017) As degeneration of cholinergic neurons in the human forebrain is one of the neuropathological features of $\mathrm{AD}$, animals with lesions of NBM are considered models of AD-type amnesia (Ahmed et al., 2004).

Memantine (MEM) is a noncompetitive N-methyl-Daspartate receptor (NMDAR) antagonist clinically used to treat $\mathrm{AD}$ in mild to severe conditions. The effect of memantine on NMDA extra-synaptic receptors is greater than that of the NMDA synaptic receptors in the same neuron, and extrasynaptic NMDARs are largely involved in causing excitotoxicity through NMDARs in AD (Carvajal et al., 2016). Previous reports support that memantine can suppress the pathological background "noise" at therapeutically relevant concentrations but preserve or even enhance the desired physiological synaptic NMDA receptor-mediated plasticity "signal" (Parsons et al., 2007). It has been shown that appropriate concentrations of memantine alter the balance between excitation and inhibition away from inhibition in the prefrontal cortex of the neuronal circuits (Povysheva \& Johnson, 2016). 
Therefore, given the role of memantine in increasing the signal-to-noise ratio and its effects on the change in the balance between excitation and inhibition away from inhibition in the prefrontal cortex, also due to the effects of memantine on neural protection, there are reports regarding the amount of memantine that does not significantly change the memory of intact mice. Therefore, this study examines the effects of memantine on the spontaneous firing frequency of CA1 pyramidal neurons by using the single-unit recording technique in the Alzheimer model and intact rats.

\section{Materials and Methods}

\section{Study animals}

A total number of 101 male Wistar rats $(200 \pm 20 \mathrm{~g})$ were obtained from the Animal House of the Ahvaz Jundishapur University of Medical Sciences (AJUMS). All rats were housed at a room temperature of $20^{\circ} \mathrm{C}$ to $24^{\circ} \mathrm{C}$ under a light/darkness cycle of $12 / 12 \mathrm{~h}$ (lights on from 7:00 AM to 7:00 PM). All rats were provided with free access to food and water. Rats were divided into two groups:

\section{Group I (n=53) includes the following subgroups:}

1) Lesion+0.2 $\mathrm{mL}$ saline: The group had surgery, and bilateral lesions were induced in NBM by an electrical method.

2) Sham+0.2 mL saline: The group had surgery, and the electrodes were placed bilaterally into NBM without any currents.

3-5) Lesion+MEM $5 \mathrm{mg} / \mathrm{kg}$, lesion+MEM $10 \mathrm{mg} /$ $\mathrm{kg}$, and lesion+MEM $20 \mathrm{mg} / \mathrm{kg}$ : The group had surgery and bilateral lesions of NBM were created by electrical method.

Group II (Intact, $\mathbf{n = 4 8}$ ) includes the following subgroups:

1) Intact $+0.2 \mathrm{~mL}$ saline: This group did not undergo any surgery.

2-4) Intact+MEM $3 \mathrm{mg} / \mathrm{kg}$, intact+MEM $5 \mathrm{mg} / \mathrm{kg}$, and intact+MEM $10 \mathrm{mg} / \mathrm{kg}$ : These groups did not undergo any surgery.

\section{Drug administration}

The drug used in this study was memantine hydrochloride (Sigma-Aldrich, CAS Number 41100-52-1), dis- solved in $0.9 \%$ injectable saline (Llorente-Ovejero et al., 2017). For each experiment, the freshly prepared solution was injected Intraperitoneally (IP).

\section{Stereotaxic surgery}

Rats were anesthetized with an intraperitoneal injection of $78 \mathrm{mg} / \mathrm{kg}$ of $10 \%$ ketamine and $3 \mathrm{mg} / \mathrm{kg}$ of $2 \%$ xylazine and placed in stereotaxic apparatus (Stoelting, USA). The head of each animal was mounted in a stereotaxic frame, and the skull was opened above NBM $(\mathrm{AP}=-1.3 \mathrm{~mm} ; \mathrm{ML}= \pm 2.8 \mathrm{~mm} ; \mathrm{DV}=-8 \mathrm{~mm})$. Then by using the Lesion Making Device (UGO Basile), the NBM electrical lesion was created in both brain hemispheres ( $0.5 \mathrm{~mA}$ for $3 \mathrm{~s})$, and the Alzheimer model was created (Hoveizi et al., 2018). One week after surgery, the animals were prepared for in vivo single-unit recording.

\section{Animal preparation for single-unit recording}

Rats were deeply anesthetized with urethane (1.2-1.5 g/kg, IP; Sigma-Aldrich) (Shahidi et al., 2017). As urethane causes difficulty in breathing by increasing the liquid release to the airways and reducing the noise caused by muscle activity during breathing, the rats were subject to surgical tracheostomy before single-unit recording. Briefly, an incision was made in the midline of the neck region, and then the soft tissues and muscles were cut longitudinally to expose the animal's trachea. At this stage, using a scalpel, a horizontal incision was made in the animal's trachea, and a $2.5-\mathrm{cm}$ polyethylene tube was sent to the lower part of the trachea. The tube was fixed with a suture, and the front of the neck was also sutured. After inserting the tube into the trachea, the animal breathed through it (Shahidi et al., 2017).

\section{Extracellular single-unit recording}

Immediately after the tracheostomy, the rat was placed in stereotaxic apparatus. Using the rat brain atlas of Paxinos and Watson and the coordinates of the dorsal hippocampus $\mathrm{CA} 1$ region $(\mathrm{AP}=-3.5 \mathrm{~mm}$; $\mathrm{ML}=$ $2.2 \mathrm{~mm}$; DV=-2.4 mm), a tungsten micro-electrode (FHC; America) with a diameter of $125 \mu \mathrm{m}$ and tip impedance $5 \mathrm{M} \Omega$ was placed in the hippocampus CA1 region (Riahi et al., 2015). The electrode was slowly lowered to reach the pyramidal cell layer of the dorsal hippocampus, where the electrical potential transferred from the microelectrode tip was examined until a neuron with a double signal-to-noise activity ratio was found. The range in which the pyramidal cells of the CA1 region are located is 0.6 to $0.8 \mathrm{~mm}$, and the electrode in this range was lowered by manual 

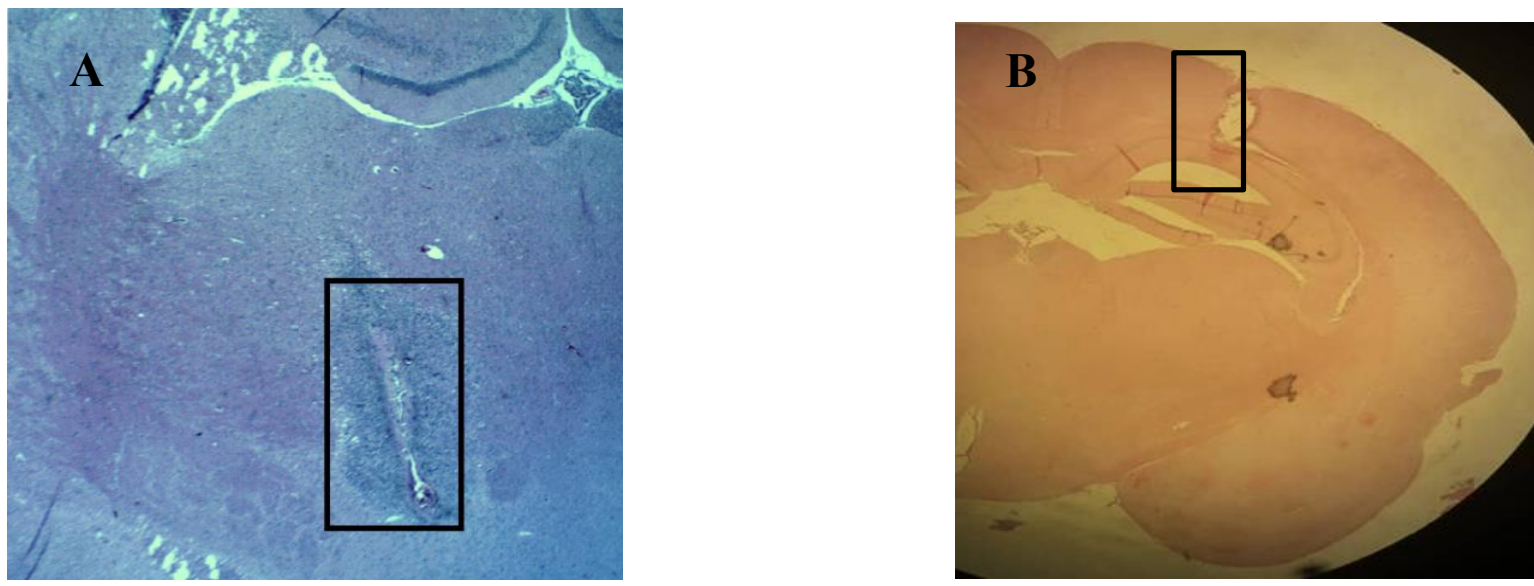

NEUR SCIENCE

Figure 1. A: Representative images showing the electrical lesion of NBM site; B: the electrophysiological recording site located in the CA1 pyramidal cells layer

Microdrive. In the CA1 region, it is possible to take a single-unit recording from each neuron with pyramidal neuron features. The pyramidal neurons of the neurons that transmit spike signals have a constant size and shape with frequencies equal to or less than 8 spike/s (Green \& Arenos, 2007). In this study, eProbe (Spike; ScienceBeam, Tehran, Iran) software was used to perform electrical recording. After finding a neuron with spontaneous activity equal to or less than 8 spike/s with a signal of the same size and shape, baseline recording was performed for $15 \mathrm{~min}$. Then, the recording was continued for another $105 \mathrm{~min}$ in saline groups with different doses of memantine after intraperitoneal injection of saline $(0.2 \mathrm{~mL})$ and memantine.
At this stage, the data were stored as streams, and then using eProbe software with offline sorting, they were stored for each $120 \mathrm{~min}$ record as Peri-Stimulus time histograms (PSTHs) with a time bin of $60 \mathrm{~s}$. The average frequency was analyzed for each $120 \mathrm{~min}$ record in pyramidal neurons in the eProbe analysis section.

\section{Histological verifications}

To confirm the tissue in the lesion group, several animals were deeply anesthetized with an intraperitoneal injection of ketamine and xylazine after 120 minutes of single-unit recording. Their brains were removed and stabilized in $10 \%$ formalin, then the sections with
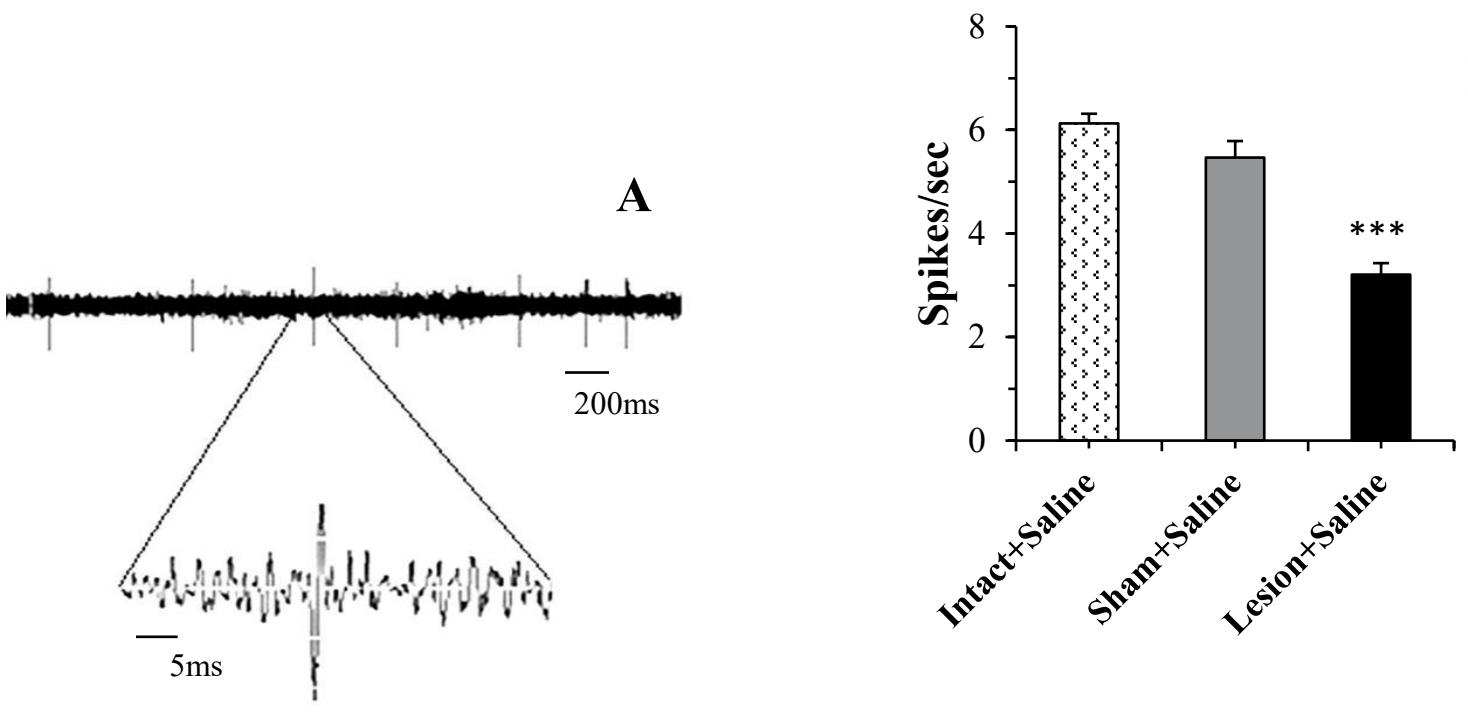

NEUR SCIENCE

Figure 2. A: A pattern of baseline spontaneous firing recorded from CA1 pyramidal neuron in intact rats; B: The mean frequency of dorsal hippocampus CA1 pyramidal neurons after saline injections.

Data are expressed as Mean \pm SEM; ${ }^{* * *} \mathrm{P}<0.001$. 


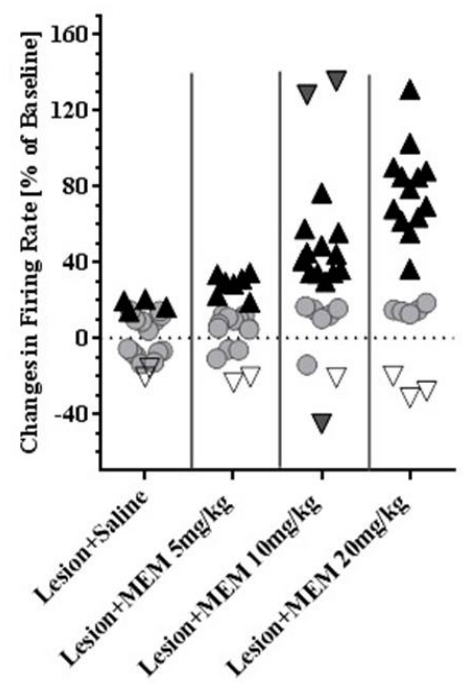

A

口Unaffected Neurons

-Excited Neurons

口Inhibited Neurons

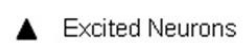

$\nabla$ Inhibited Neurons

Unaffected Neurons

$\nabla$ Excluded Neurons

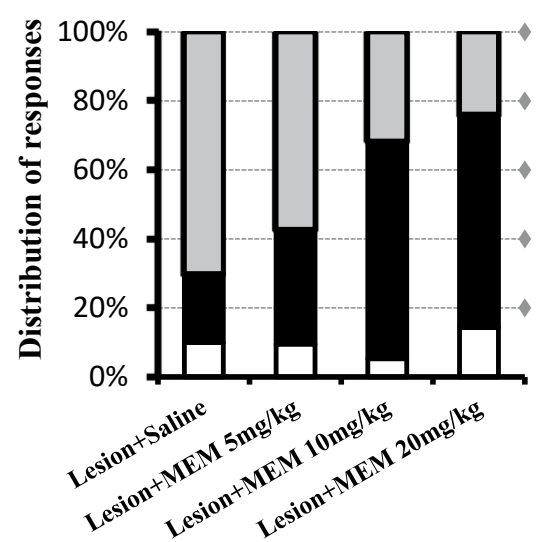

C

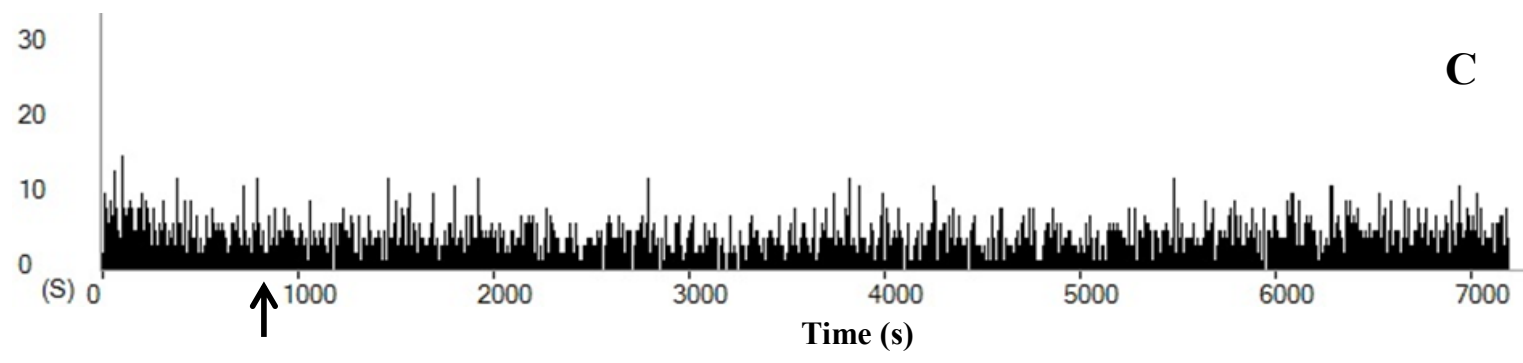

Saline

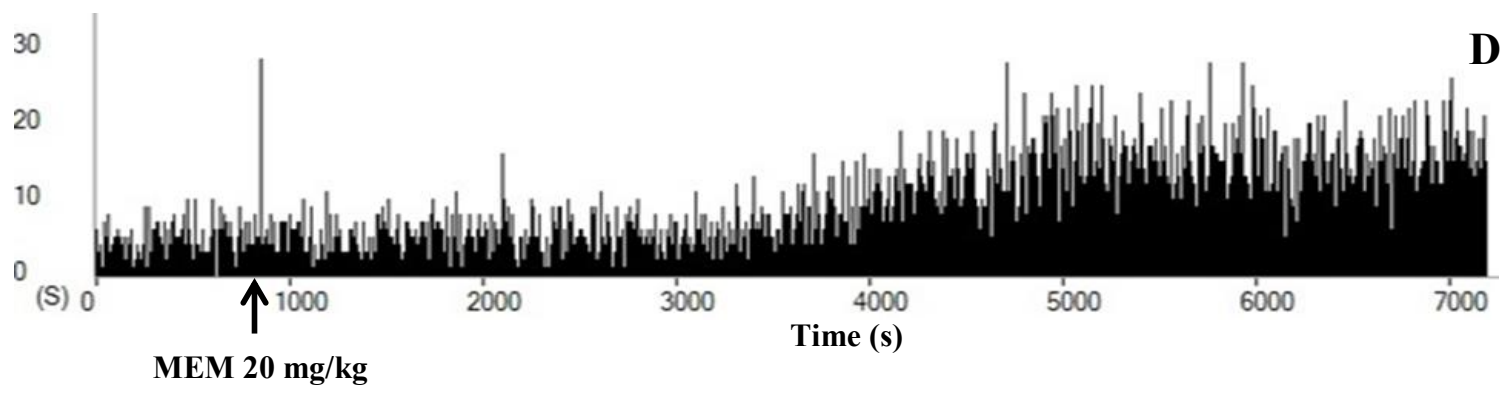

Figure 3. Excitation of most CA1 pyramidal neurons due to intraperitoneal injection of memantine or saline

NEURSCIENCE

A: Distribution of neuronal responses to memantine or saline injection; B: The Chi-square test (data are presented as the percentage of response type), the excitatory effects of intraperitoneal injection of saline; and C: Memantine $20 \mathrm{mg} / \mathrm{kg}$ (D) on $120 \mathrm{~min}$ of single-unit recording in Alzheimer rat model.

a thickness of $50 \mu \mathrm{m}$ were prepared from the lesion of NBM and the electrode entrance of dorsal hippocampus CA1. These sections were stained with hematoxylin and eosin staining ( $\mathrm{H} \& \mathrm{E}$ ) and used for comparison with the atlas of Paxinos and Watson (Figure 1).

\section{Statistical analysis}

The study results were presented as Mean \pm SEM, and neurons with excessive increased or decreased responses were shown as excluded neurons in the scatterplots but removed in the next steps. The Chi-square and Fisher exact-tests were used to compare the excitatory, inhibitory, and unaffected neurons between the two groups. In addition, for measuring the effect of memantine on neural firing rate, the paired samples t-test was used in the memantine group. To evaluate the cumulative effects of memantine and saline, 1-way ANOVA and Tukey test were used. Statistical tests were performed using SPSS v. 16 and $\mathrm{P}<0.05$ as the significance level. 


\section{Results}

Effects of bilateral electrical lesions of NBM on the spontaneous responses of CA1 pyramidal neurons

As already explained, the pyramidal neurons have a frequency equal to or less than 8 spikes/s (Figure 2A). To investigate the effect of bilateral electrical lesion of $\mathrm{NBM}$ on the firing of pyramidal neurons by 1-way ANOVA and post-hoc Tukey test, it was shown that the mean frequency of dorsal hippocampus CA1 pyramidal neurons after saline injections in the lesion + saline $(n=14)$ group had a significant difference with the intact + saline $(\mathrm{n}=11)$ and sham + saline $(\mathrm{n}=13)$ groups $(\mathrm{P}<0.001)$. Also, it was shown that there is no significant difference between the mean frequencies of pyramidal neurons in the intact + saline and sham + saline groups (Figure 2B).

Effects of memantine intraperitoneal injection on the spontaneous responses of CA1 pyramidal neurons in Alzheimer rat model

In this study, in the lesion+saline group, out of 20 neurons in 14 rats, 14 neurons $(70 \%)$ were unaffected, 4 $(20 \%)$ were excited, and $2(10 \%)$ were inhibited. In the lesion+MEM $5 \mathrm{mg} / \mathrm{kg}$ group, out of 21 neurons in 14 rats, 12 neurons (57.14\%) were unaffected, 7 (33.33\%) were excited and $2(9.5 \%)$ were inhibited. In the lesion+MEM $10 \mathrm{mg} / \mathrm{kg}$ group, out of 19 neurons in 13 rats, 6 neurons (31.6\%) were unaffected, $12(63.2 \%)$ were excited and $1(5.2 \%)$ was inhibited. In the lesion+MEM $20 \mathrm{mg} / \mathrm{kg}$ group, out of 21 neurons in 12 rats, 5 neurons (23.8\%) were unaffected, $13(61.9 \%)$ were excited, and $3(14.3 \%)$ were inhibited (Figure 3A and 3B).

The Chi-square and Fisher exact-tests to compare the excitatory, inhibitory, and unaffected responses among the groups showed significant differences between the lesion+saline group with lesion+MEM $10 \mathrm{mg} / \mathrm{kg}$ $(\mathrm{P}<0.05)$ and Lesion+MEM $20 \mathrm{mg} / \mathrm{kg}(\mathrm{P}<0.01)$ groups.

In this study, to investigate the effect of saline and memantine on the firing rate of pyramidal neurons, a 1-way ANOVA test, and Tukey test were used. It was shown that after injection of saline and memantine, there were significant differences between average frequencies of CA1 pyramidal neurons in the lesion+saline group with lesion+MEM $10 \mathrm{mg} / \mathrm{kg}(\mathrm{P}<0.01)$ and lesion+MEM 20 $\mathrm{mg} / \mathrm{kg}(\mathrm{P}<0.001)$ groups (Figure $4 \mathrm{~A})$.

In addition, to study the effect of memantine on the neural firing rate of excited neurons in Lesion+MEM $20 \mathrm{mg} / \mathrm{kg}$, the paired sample t-test was used. The results of this test showed that after intraperitoneal injection of memantine in the subclass of neurons with an excitatory
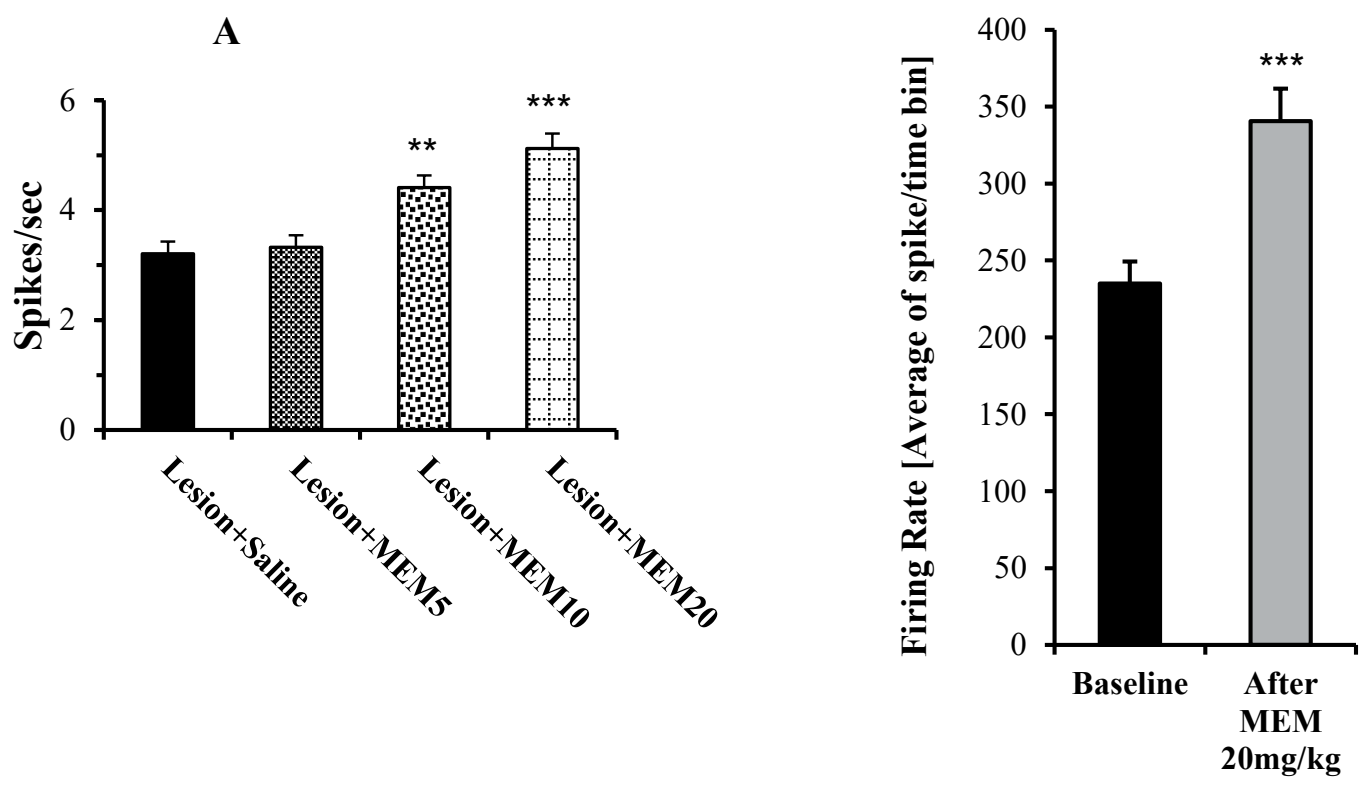

B

\section{NEUR SCIENCE}

Figure 4. The mean frequency of dorsal hippocampus CA1 pyramidal neurons after saline and memantine injection (1-way anova and tukey test results)

Response of neurons excitatory $(\mathrm{n}=13)$ after intraperitoneal injection of memantine. Paired sample $\mathrm{t}$-test $(\mathrm{B})$ in Alzheimer rat model. Data are expressed as Mean \pm SEM, ${ }^{* *} \mathrm{P}<0.001,{ }^{* * *} \mathrm{P}<0.001$. 

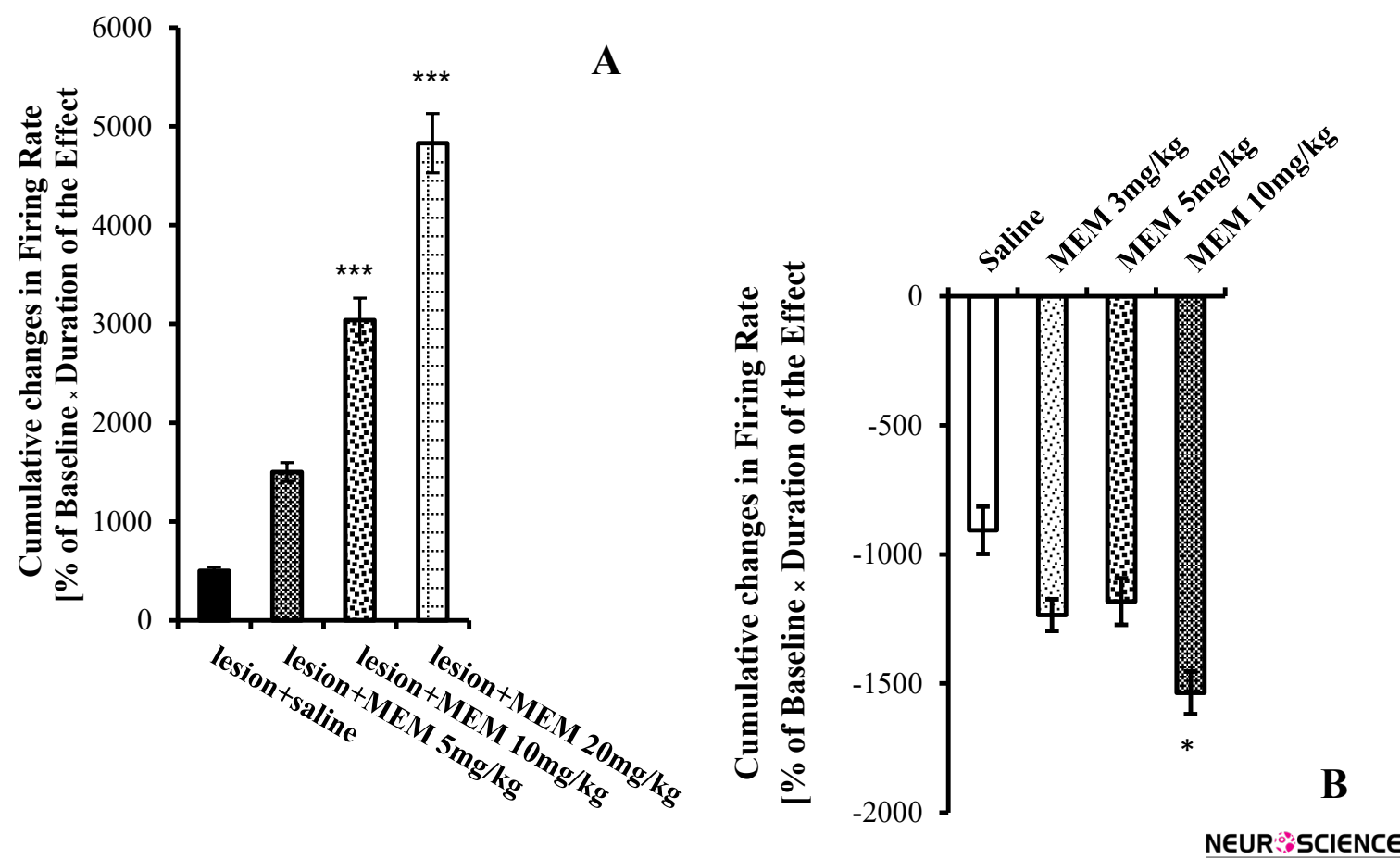

Figure 5. Cumulative changes in firing rate subclass of neurons with excitatory response in alzheimer rat model

The subclass of neurons with inhibitory response in intact rats (B) after memantine IP injection using 1-way ANOVA and Tukey test. Data are expressed as Mean $\pm \mathrm{SEM},{ }^{*} \mathrm{P}<0.05,{ }^{* * *} \mathrm{P}<0.001$.

response $(\mathrm{n}=13)$, the mean firing rate was significantly different from baseline firing $(\mathrm{P}<0.001)$ (Figure 4B).

The results of ANOVA and Tukey tests show that the cumulative changes in firing rate (time effect of the drug $\times \%$ frequency changes from baseline) in the excited neurons of lesion+MEM $10 \mathrm{mg} / \mathrm{kg}(\mathrm{P}<0.001)$ and lesion+MEM $20 \mathrm{mg} / \mathrm{kg}(\mathrm{P}<0.001)$ groups had a significant difference with the lesion+saline group (Figure 5A).

Effects of memantine intraperitoneal injection on the spontaneous responses of CA1 pyramidal neurons in intact rats

In the Intact + saline group, out of 22 neurons in 11 rats, 16 neurons $(72.7 \%)$ were unaffected, 3 (13.65\%) were excited, and $3(13.65 \%)$ were inhibited. In the intact+MEM $3 \mathrm{mg} / \mathrm{kg}$ group, out of 22 neurons in 12 rats, 13 neurons $(59.09 \%)$ were unaffected, and 9 $(40.9 \%)$ were inhibited. In the intact+MEM $5 \mathrm{mg} / \mathrm{kg}$ group, out of 22 neurons in 13 rats, 6 neurons $(27.3 \%)$ were unaffected and $16(72.7 \%)$ were inhibited. In the intact+MEM $10 \mathrm{mg} / \mathrm{kg}$ group, out of 21 neurons in 12 rats, 3 neurons (14.3\%) were unaffected and 18 $(85.7 \%)$ were inhibited (Figure 6A and 6B). The Chisquare and Fisher exact-tests were done to compare the excitatory, inhibitory, and unaffected responses among the groups. The results showed significant differences between the intact + saline group with intact + MEM 3 $\mathrm{mg} / \mathrm{kg}(\mathrm{P}<0.01)$, intact+MEM $5 \mathrm{mg} / \mathrm{kg}(\mathrm{P}<0.001)$, and intact+MEM $10 \mathrm{mg} / \mathrm{kg}(\mathrm{P}<0.001)$ groups.

In this study, to investigate the effect of saline and memantine on the firing rate of pyramidal neurons in intact rats, after injection of saline and memantine, we observed a significant difference between average frequencies of CA1 pyramidal neurons in the intact + saline and Intact+MEM $10 \mathrm{mg} / \mathrm{kg}$ groups $(\mathrm{P}<0.001)$ (Figure 7A).

In addition, to study the effect of memantine on the neural firing rate of inhibited neurons in the intact+MEM $10 \mathrm{mg} / \mathrm{kg}$ group, the paired sample t-test was used. The results of this test showed that after intraperitoneal injection of memantine in the subclass of neurons with an inhibited response $(n=18)$, the mean firing rate was significantly different from baseline firing $(\mathrm{P}<0.001)$ (Figure 7B).

The results of ANOVA and Tukey tests show that the cumulative changes in firing rate (time effect of the drug $\times \%$ frequency changes from baseline) in inhibited neurons of the intact+MEM $10 \mathrm{mg} / \mathrm{kg}$ group had a significant difference with the intact + saline group $(\mathrm{P}<0.05)$ (Figure $5 \mathrm{~B})$. 


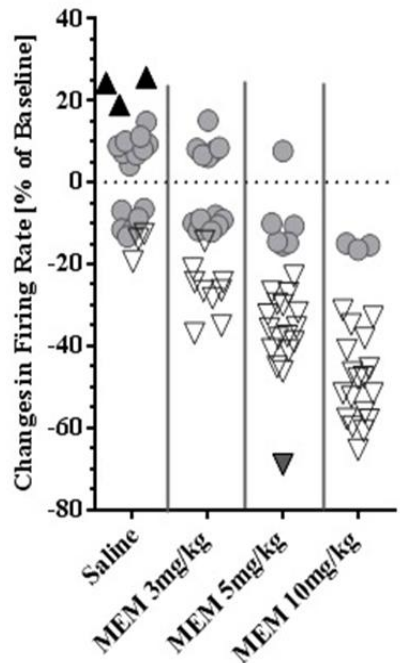

A

口Unaffected Neurons

Excited Neurons

口Inhibited Neurons

- Excited Neurons

$\nabla$ Inhibited Neurons

- Unaffected Neurons

$\nabla$ Excluded Neurons
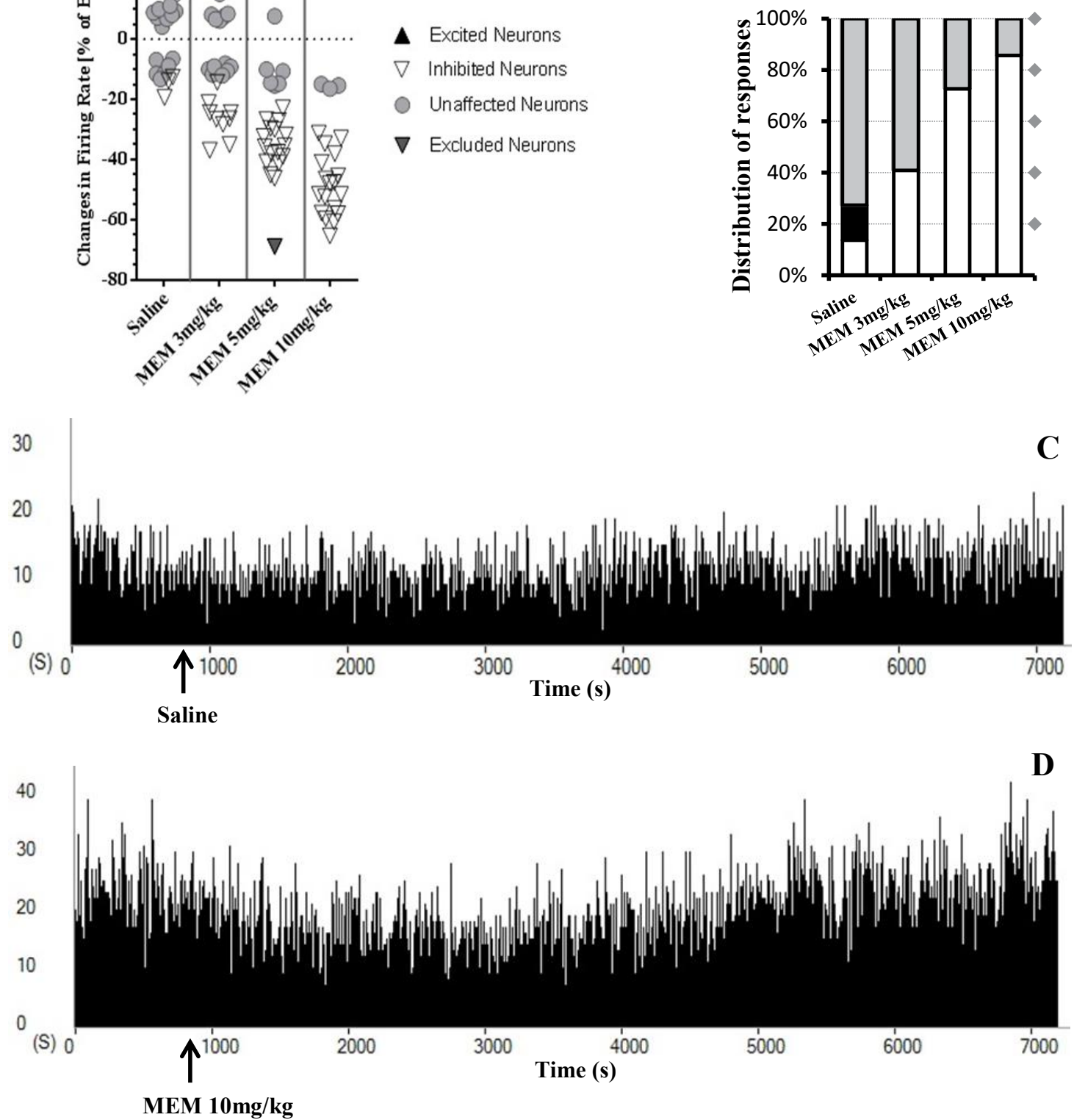

Figure 6. Inhibition of most CA1 pyramidal neurons due to intraperitoneal injection of memantine or saline NEUR SCIENCE

A: Distribution of neuronal responses to memantine or saline injection; B: the Chi-square test (Data are presented as the percentage of response type), the inhibitory effects of intraperitoneal injection of Saline; and C: Memantine $10 \mathrm{mg} / \mathrm{kg}$; D: on 120 minutes of single-unit recording in intact rats.

Comparing the effect of memantine intraperitoneal injection on the spontaneous responses of peripheral Ca1 neurons in Alzheimer model and intact rats

The Chi-square and Fisher exact-tests were done to compare the excitatory, inhibitory, and unaffected responses among the groups. The results showed a significant difference between the lesion+MEM $5 \mathrm{mg} / \mathrm{kg}$ and intact+MEM 5 $\mathrm{mg} / \mathrm{kg}$ groups $(\mathrm{P}<0.001)$. In addition, there was a significant difference between lesion + MEM $10 \mathrm{mg} / \mathrm{kg}$ and intact+MEM $10 \mathrm{mg} / \mathrm{kg}$ groups $(\mathrm{P}<0.001)$ (Figure 3B and Figure 6B).

\section{Discussion}

Nervous system disorders (often before memory loss) are commonly found in elderly patients with Alzheimer 

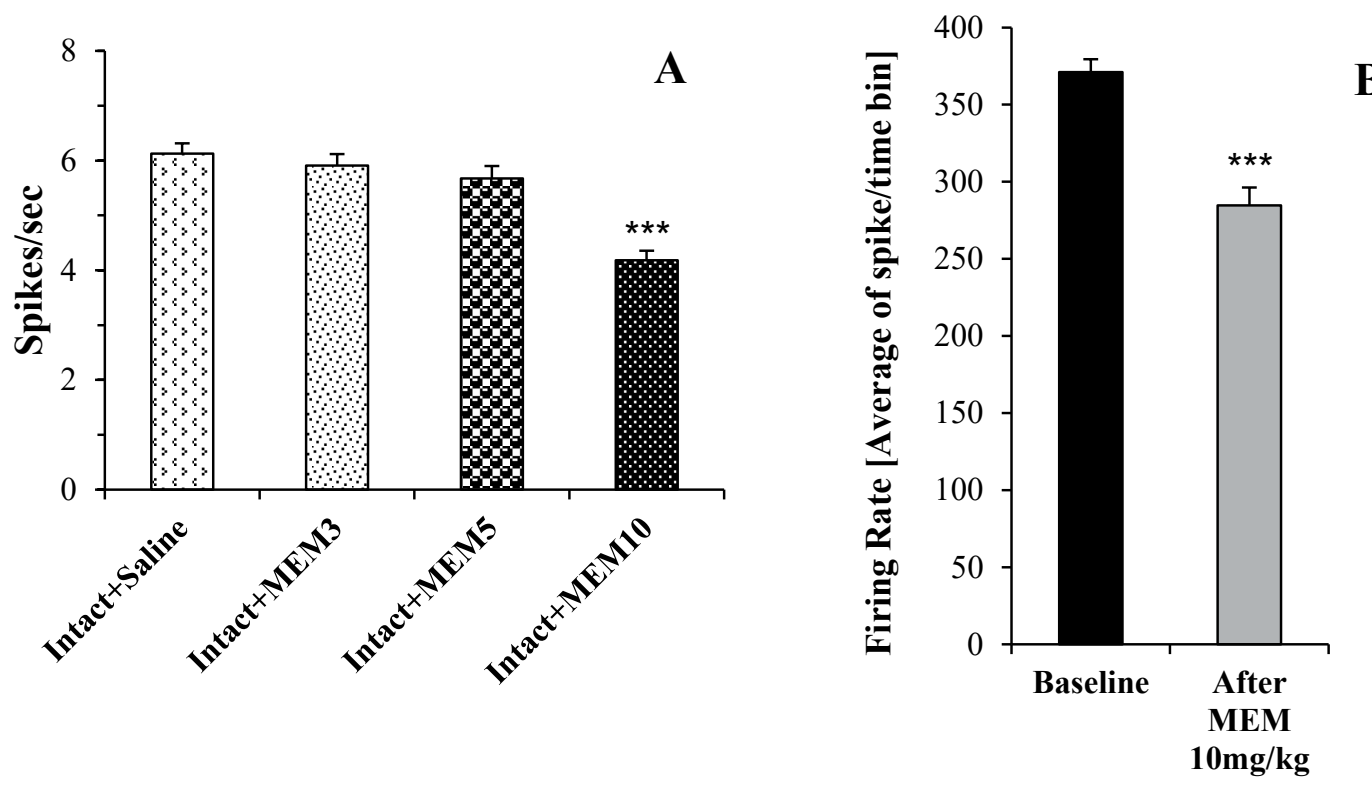

NEUR:SCIENCE

Figure 7. The mean frequency of dorsal hippocampus CA1 pyramidal neurons after saline and memantine injections

A: Response of neurons inhibited $(n=18)$ after intraperitoneal injection of memantine; $B$ : The paired sample $t$-test in intact rats. Data are expressed as Mean \pm SEM. ${ }^{* *} \mathrm{P}<0.001$.

disease due to the accumulation of amyloid sediments in their brains, indicating a preliminary event in the pathogenesis of Alzheimer disease (Ahnaou et al., 2017). The single-unit recording is a standard method for studying the frequency of neuron firing. The results of this study indicate that bilateral lesions of NBM and Alzheimer induction reduce the frequency of neuron firing in the hippocampal CA1 pyramidal neurons compared with intact rats, which is in line with the results of previous reports. In these reports, increasing the threshold for triggering the action potential and reducing the action potential in the hippocampal CA1 pyramidal neurons (Hatch et al., 2017), as well as the reduction of the electrical activity of the hippocampal CA1 pyramidal neurons, are shown in the transgenic mouse models. Additionally, the bilateral intra-hippocampus injection of $A \beta$ resulted in a significant reduction in the average number of spikes/bin (Farbood et al. 2017; Shabani et al., 2016) and inhibition of long-term potentiation (LTP) induction by High-Frequency Stimulation (HFS) (Shahidi et al., 2017) in granular hippocampal dentate gyrus cells. The effect of NBM lesions was also shown on the reduction of base synapse response, paired-pulse response, and LTP in the dentate gyrus. These reports indicate that although the NBM does not introduce direct cholinergic splits to the hippocampus, its lesion affects the long-term and short-term plasticity in dentate gyrus cells (Hosseini et al., 2017).
It has been shown that the binding of memantine to NMDA receptors in the nerve tissue inhibits the entry of calcium, significantly reduces the activity of neuronal synthase nitric oxide, and protects nerve cells (Liu et al., 2017; Nyakas et al., 2011). Additionally, excessive excitation of NMDA receptors can interfere with LTP and learning. For example, intraperitoneal injection of NMDA disrupted the passive avoidance learning and inhibition of mean LTP in the hippocampal CA1 region, and the reduction of these effects was caused by meantime (Zajaczkowski et al., 1997).

The study results indicate that the neuronal firing frequency in the hippocampal CA1 pyramidal neurons in Alzheimer rats increased after the intraperitoneal injection of memantine $10 \mathrm{mg} / \mathrm{kg}(\mathrm{P}<0.01)$ and memantine $20 \mathrm{mg} / \mathrm{kg}(\mathrm{P}<0.001)$. In accordance with these observations, Klyubin et al. (2011) reported that memantine reduces the inhibitory effects of $A \beta$ on the induction of LTP in CA3-to-CA1 synapses (Nyakas et al., 2011). Electrophysiological evidence suggests that memantine effectively inhibits excessive flow in the extrasynaptic NMDA receptors, while the synaptic receptor's activity remains relatively normal (Xia et al., 2010). Li et al. showed that soluble $\mathrm{A} \beta$ oligomers cause excessive activity of the extrasynaptic NMDA receptors and disruptions in synaptic plasticity ( $\mathrm{Li}$ et al., 2011). Therefore, memantine can improve memory in the Alzheimer model by inhibiting the extrasynaptic NMDA receptors. 
In addition, in several studies, higher levels of acetylcholine have been reported after acute dosing of NMDA receptor antagonists (Giovannini et al., 1994; Hutson \& Hogg, 1996; Ihalainen et al., 2011; Shearman et al., 2006). For example, in rats with Fimbria-fornix lesions, by the acute intraperitoneal injection of memantine 5 and $10 \mathrm{mg} / \mathrm{kg}$, the extracellular acetylcholine levels in the hippocampus increased by $167 \%$ and $250 \%$, respectively. In this study, $10 \mathrm{mg} / \mathrm{kg}$ of memantine increased extracellular acetylcholine levels by 3.5 times greater than the baseline level in the hippocampus and neocortex (Ihalainen et al., 2011). Electrophysiological studies have shown that memantine produces excitement effects on cholinergic signaling in the hippocampus via muscarinic receptors (Drever et al., 2007).

Electrophysiological studies also indicate that memantine binds to the site of the ion channel of the NMDA receptor with a low-affinity and voltage-dependent mode so that in the case of continued excitation in pathological conditions, this binding remains despite the loose binding of magnesium ions. However, in physiological conditions where high concentrations of glutamate are produced in transient mode, memantine is isolated from the receptor, and the transfer function in the receptor remains normal (Parsons et al., 2013). Thus, in Alzheimer disease, memantine helps the better diagnosis of physiological signals by reducing the noise background caused by glutamate signaling impairment (Danysz et al., 2000).

Generally, it seems that memantine in the Alzheimer rat model enhances the spontaneous firing frequency of hippocampal CA1 pyramidal neurons by modifying neuronal damage due to oxidative stress, decreasing LTP disorder, reducing background noise, changing the balance between excitation and inhibition away from inhibition and exciting effects on cholinergic signaling.

On the other hand, given the neuroprotective effects of memantine, several experiments have been carried out to achieve the amount of memantine that does not cause memory impairment and has tolerable side effects in intact subjects (Creeley et al., 2006). In the present study, the effect of different doses of memantine on the electrical activity of CA1 pyramidal neurons in intact rats indicated the inhibitory effects of memantine at doses of 3,5 , and $10 \mathrm{mg} / \mathrm{kg}$ on the firing frequency of these neurons. The study of the mean firing frequency of CA1 pyramidal neurons showed that $10 \mathrm{mg} / \mathrm{kg}$ memantine significantly decreased the electrical activity of these neurons $(\mathrm{P}<0.001)$.
Studies have shown that, in the Morris water maze test, the intraperitoneal injection of $20 \mathrm{mg} / \mathrm{kg}$ of memantine in intact rats caused short-term memory impairment, while $5 \mathrm{mg} / \mathrm{kg}$ of memantine had no effect (Duda et al., 2016). On the other hand, it has been shown that cumulative doses of memantine $(4,8$, and $16 \mathrm{mg} / \mathrm{kg}$ IV) reduced the firing rate in the hippocampal CA1 in intact rats (Szegedi et al., 2010). Besides, studies in the platform relocation version of the water maze show that 5 and 10 $\mathrm{mg} / \mathrm{kg}$ memantine cause cognitive impairments in 6- to 12-week-old rats (Saab et al., 2011). Additionally, acute intraperitoneal injection of $20 \mathrm{mg} / \mathrm{kg}$ memantine reduces functional memory in the Allothetic Place Avoidance Alternate Task (Wesierska et al., 2013). However, in the study by Zajaczkowski et al., the intraperitoneal injection of $20 \mathrm{mg} / \mathrm{kg}$ of memantine did not affect functional memory in the radial maze (Zajaczkowski et al., 2000). Also, some studies have shown that at the therapeutic concentrations, memantine captivates one-third of NMDA receptors and that these memantine levels have neuroprotective effects while they have no significant effect on learning (More et al., 2008). Klyubin et al. (2011) demonstrated that intraperitoneal injection of memantine $10 \mathrm{mg} / \mathrm{kg}$ at $40 \mathrm{~min}$ prior to HFS had no significant effect on LTP at CA3-to-CA1 synapses in intact rats. However, memantine $(20 \mathrm{mg} / \mathrm{kg}$ ) caused complete LTP inhibition in these synapses (Nyakas et al., 2011). Also, it was shown that 5 and $20 \mathrm{mg} / \mathrm{kg}$ of memantine have no significant effect on LTP induced by HFS in the dentate gyrus of rats (Li et al., 2013). It seems that the differences between the findings of these studies are due to the method (LTP and single-unit recording) and region of electrical recording (CA3-to-CA1 synapses, CA1 pyramidal neurons, and dentate gyrus).

The positive effects of memantine on the memory of intact mice have also been shown in some studies. For example, Zoladz et al. (2006) argued that 5 and $7.5 \mathrm{mg} /$ $\mathrm{kg}$ of memantine in the Morris water maze test improves spatial memory in intact adult male rats. Moreover, in the radial maze test, the acute intraperitoneal injection of 0.3 and $0.56 \mathrm{mg} / \mathrm{kg}$ of memantine 20 minutes prior to the acquisition reduced the error and improved memory in the memory recall test ( 18 hours after the last acquisition session) (Wise \& Lichtman, 2007). It seems that memantine affects memory enhancement in these cases through the imbalance between GABAergic and glutamatergic functions and higher levels of extracellular acetylcholine (Drever et al., 2007; Ihalainen et al., 2011; Povysheva \& Johnson, 2016; Shearman et al., 2006; Yamaguchi et al., 2013). Also, the differences in the effective amount of memantine are related to the treatment method (oral and intraperitoneal), the duration of treatment (acute and 
chronic), and the treatment time (before training, immediately after training, and before recalling).

Therefore, according to the results of the current study under in vivo conditions, memantine increases the spontaneous firing frequency of CA1 pyramidal neurons in rats with electrical lesions of NBM as a model of Alzheimer disease in a dose-dependent manner. Also, in intact adult male rats, it was shown that low-dose memantine, contrary to its high dose, did not decrease the electrical activity of CA1 pyramidal neurons. So, considering the memantine neuroprotective effects reported in other studies, these findings support the use of lowdose memantine in pre-treatment studies of Alzheimer disease.

\section{Ethical Considerations}

\section{Compliance with ethical guidelines}

The Ethics Committee of Shahid Chamran University of Ahvaz approved the research protocol (Code: EE/97, $24,3061243 /$ scu.ac.ir).

\section{Funding}

The research project was funded by Shahid Chamran University, Ahvaz.

\section{Authors' contributions}

All authors equally contributed to preparing this article.

\section{Conflict of interest}

The authors declared no conflict of interest.

\section{Acknowledgments}

The authors would like to thank Shahid Chamran University of Ahvaz, Deputy of Research for cooperation and assistance in the project.

\section{References}

Ahmed, M. M., Hoshino, H., Chikuma, T., Yamada, M., \& Kato, T. (2004). Effect of memantine on the levels of glial cells, neuropeptides, and peptide-degrading enzymes in rat brain regions of ibotenic acid-treated alzheimer's disease model. Neuroscience, 126(3), 639-649. [DOI:10.1016/j.neuroscience.2004.04.024] [PMID]
Ahnaou, A., Moechars, D., Raeymaekers, L., Biermans, R., Manyakov, N. V., \& Bottelbergs, A., et al. (2017). Emergence of early alterations in network oscillations and functional connectivity in a tau seeding mouse model of Alzheimer's disease pathology. Scientific Reports, 7(1), 14189. [PMID] [PMCID]

Carvajal, F. J., Mattison, H. A., \& Cerpa, W. (2016). Role of NMDA receptor-mediated glutamatergic signaling in chronic and acute neuropathologies. Neural Plasticity, 2016 2701526. [PMID] [PMCID]

Castaneda, M. T., Lopez, E. D., Touhami, A., Tovar, R., Ortega, M. R., \& Rodriguez, J. M. (2015). Neuroprotection of medial septal cholinergic neurons by memantine after intralateral septal injection of Abeta1-40. Neuroreport, 26(8), 450-454. [PMID]

Creeley, C., Wozniak, D. F., Labruyere, J., Taylor, G. T., \& Olney, J. W. (2006). Low doses of memantine disrupt memory in adult rats. The Journal of Neuroscience, 26(15), 3923-3932. [PMID] [PMCID]

Danysz, W., Parsons, C. G., Mobius, H. J., Stoffler, A., \& Quack, G. (2000). Neuroprotective and symptomatological action of memantine relevant for Alzheimer's disease--a unified glutamatergic hypothesis on the mechanism of action. Neurotoxicity Research, 2(2-3), 85-97. [PMID]

Drever, B. D., Anderson, W. G., Johnson, H., O'Callaghan M., Seo, S., \& Choi, D. Y., et al. (2007). Memantine acts as a cholinergic stimulant in the mouse hippocampus. Journal of Alzheimer's disease : JAD, 12(4), 319-333. [PMID]

Du, X., Wang, X., \& Geng, M. (2018). Alzheimer's disease hypothesis and related therapies. Translational Neurodegeneration, 7, 2. [PMID] [PMCID]

Duda, W., Wesierska, M., Ostaszewski, P., Vales, K., Nekovarova, T., \& Stuchlik, A. (2016). MK-801 and memantine act differently on short-term memory tested with differen time-intervals in the Morris water maze test. Behavioural Brain Research, 311, 15-23. [PMID]

Farbood, Y., Shabani, S., Sarkaki, A., Mard, S. A., Ahangarpour, A., \& Khorsandi, L. (2017). Peripheral and central administration of T3 improved the histological changes, memory and the dentate gyrus electrophysiological activity in an animal model of Alzheimer's disease. Metabolic Brain Disease, 32(3), 693-701. [PMID]

Giovannini, M. G., Camilli, F., Mundula, A., \& Pepeu, G. (1994). Glutamatergic regulation of acetylcholine output in different brain regions: a microdialysis study in the rat. $\mathrm{Neu}$ rochemistry International, 25(1), 23-26. [DOI:10.1016/01970186(94)90048-5]

Green, J. T., \& Arenos, J. D. (2007). Hippocampal and cerebellar single-unit activity during delay and trace eyeblink conditioning in the rat. Neurobiology of Learning and Memory, 87(2), 269-284. [PMID] [PMCID]

Hatch, R. J., Wei, Y., Xia, D., \& Gotz, J. (2017). Hyperphosphorylated tau causes reduced hippocampal CA1 excitability by relocating the axon initial segment. Acta Neuropathologica, 133(5), 717-730. [PMID] [PMCID]

Hosseini, N., Alaei, H., Reisi, P., \& Radahmadi, M. (2017). The effects of NBM- lesion on synaptic plasticity in rats. Brain Research, 1655, 122-127. [PMID] 
Hoveizi, E., Mohammadi, T., Moazedi, A. A., Zamani, N., \& Eskandary, A. (2018). Transplanted neural-like cells improve memory and Alzheimer-like pathology in a rat model. Cytotherapy, 20(7), 964-973. [PMID]

Hutson, P. H., \& Hogg, J. E. (1996). Effects of and interactions between antagonists for different sites on the NMDA receptor complex on hippocampal and striatal acetylcholine efflux in vivo. European Journal of Pharmacology, 295(1), 45-52. [DOI:10.1016/0014-2999(95)00634-6]

Ihalainen, J., Sarajärvi, T., Rasmusson, D., Kemppainen, S., Keski-Rahkonen, P., \& Lehtonen, M., et al. (2011). Effects of memantine and donepezil on cortical and hippocampal acetylcholine levels and object recognition memory in rats. Neuropharmacology, 61(5-6), 891-899. [PMID]

Klyubin, I., Wang, Q., Reed, M. N., Irving, E. A., Upton N, Hofmeister, J., et al. (2011). Protection against A $\beta$-mediated rapid disruption of synaptic plasticity and memory by memantine. Neurobiol Aging, 32(4), 614-623. [DOI:10.1016/j. neurobiolaging.2009.04.005] [PMID]

Knox, D. (2016). The role of basal forebrain cholinergic neurons in fear and extinction memory. Neurobiology of Learning and Memory, 133, 39-52. [PMID] [PMCID]

Li, F., Chen, X., Wang, F., Xu, S., Chang, L., \& Anwyl, R., et al. (2013). Chronic pre-treatment with memantine prevents amyloid-beta protein-mediated long-term potentiation disruption. Neural Regeneration Research, 8(1), 49-55. [PMID] [PMCID]

Li, S., Jin, M., Koeglsperger, T., Shepardson, N. E., Shankar, G. M., \& Selkoe, D. J. (2011). Soluble Abeta oligomers inhibit long-term potentiation through a mechanism involving excessive activation of extrasynaptic NR2B-containing NMDA receptors. The Journal of Neuroscience: The Official Journal of the Society for Neuroscience, 31(18), 6627-6638. [PMID] [PMCID]

Liu, Z., Yang, S., Jin, X., Zhang, G., Guo, B., Chen, H., et al. (2016). Synthesis and biological evaluation of memantine nitrates as a potential treatment for neurodegenerative diseases. MedChem Comm, 8(1), 135-147. [PMID] [PMCID]

Llorente-Ovejero, A., Manuel, I., Giralt, M. T., \& RodríguezPuertas, R. (2017). Increase in cortical endocannabinoid signaling in a rat model of basal forebrain cholinergic dysfunction. Neuroscience, 362, 206-218. [PMID]

Morè, L., Gravius, A., Nagel, J., Valastro, B., Greco, S., \& Danysz, W. (2008). Therapeutically relevant plasma concentrations of memantine produce significant L-N-methylD-aspartate receptor occupation and do not impair learning in rats. Behavioural Pharmacology, 19(7), 724-734. [PMID]

Nyakas, C., Granic, I., Halmy, L. G., Banerjee, P., \& Luiten, P. G. (2011). The basal forebrain cholinergic system in aging and dementia. Rescuing cholinergic neurons from neurotoxic amyloid-beta42 with memantine. Behavioural Brain Research, 221(2), 594-603. [PMID]

Panocka, I., Sagratella, S., Scotti de Carolis, A., Zeng, Y. C., \& Amenta, F. (1995). Microanatomical and electrophysiological changes of the rat dentate gyrus caused by lesions of the nucleus basalis magnocellularis. Neuroscience Letters, 190(3), 207-211. [DOI:10.1016/0304-3940(95)11527-4]
Parsons, C. G., Danysz, W., Dekundy, A., \& Pulte, I. (2013) Memantine and cholinesterase inhibitors: Complementary mechanisms in the treatment of Alzheimer's disease. Neurotoxicity Research, 24(3), 358-369.. [PMID] [PMCID]

Parsons, C. G., Stöffler, A., \& Danysz, W. (2007). Memantine: A NMDA receptor antagonist that improves memory by restoration of homeostasis in the glutamatergic system--too little activation is bad, too much is even worse. Neuropharmacology, 53(6), 699-723. [PMID]

Povysheva, N. V., \& Johnson, J. W. (2016). Effects of memantine on the excitation-inhibition balance in prefrontal cortex. Neurobiology of Disease, 96, 75-83. [PMID] [PMCID]

Riahi, E., Arezoomandan, R., Fatahi, Z., \& Haghparast, A. (2015). The electrical activity of hippocampal pyramidal neuron is subjected to descending control by the brain orexin/hypocretin system. Neurobiology of Learning and Memory, 119, 93-101. [PMID]

Saab, B. J., Luca, R. M., Yuen, W. B., Saab, A. M., \& Roder, J. C. (2011) Memantine affects cognitive flexibility in the Morris water maze. Journal of Alzheimer's Disease: JAD, 27(3), 477-482. [PMID]

Shabani, S., Sarkaki, A., Ali Mard, S., Ahangarpour, A., Khorsandi, L., \& Farbood, Y. (2016). Central and peripheral administrations of levothyroxine improved memory performance and amplified brain electrical activity in the rat model of Alzheimer's disease. Neuropeptides, 59, 111-116. [PMID]

Shahidi, S., Zargooshnia, S., Asl, S. S., Komaki, A., \& Sarihi, A. (2017). Influence of $\mathrm{N}$-acetyl cysteine on beta-amyloidinduced Alzheimer's disease in a rat model: A behavioral and electrophysiological study. Brain Research Bulletin, 131, 142-149. [PMID]

Shearman, E., Rossi, S., Szasz, B., Juranyi, Z., Fallon, S., Pomara, N., et al. (2006). Changes in cerebral neurotransmitters and metabolites induced by acute donepezil and memantine administrations: A microdialysis study. Brain Research Bulletin, 69(2), 204-213. [PMID]

Szegedi, V., Juhász, G., Parsons, C. G., \& Budai, D. (2010). In vivo evidence for functional NMDA receptor blockade by memantine in rat hippocampal neurons. Journal of Neural Transmission (Vienna, Austria : 1996), 117(10), 1189-1194. [PMID]

Wesierska, M. J., Duda, W., \& Dockery, C. A. (2013). Lowdose memantine-induced working memory improvement in the allothetic place avoidance alternation task (APAAT) in young adult male rats. Frontiers in Behavioral Neuroscience, 7, 203. [PMID] [PMCID]

Wise, L. E., \& Lichtman, A. H. (2007). The uncompetitive Nmethyl-D-aspartate (NMDA) receptor antagonist memantine prolongs spatial memory in a rat delayed radial-arm maze memory task. European Journal of Pharmacology, 575(1 3), 98-102. [PMID] [PMCID]

Xia, P., Chen, H. S., Zhang, D., \& Lipton, S. A. (2010). Memantine preferentially blocks extrasynaptic over synaptic NMDA receptor currents in hippocampal autapses. The Journal of Neuroscience: The Official Journal of The Society for Neuroscience, 30(33), 11246-11250. [PMID] [PMCID]

Yamaguchi, Y., Takeda, K., \& Hino, M. (2013). Combination effects of ZSET1446/ST101 with memantine on cognitive function and extracellular acetylcholine in the hippocampus. Journal of Pharmacological Sciences, 123(4), 347-355. [PMID] 
Zajaczkowski, W., Frankiewicz, T., Parsons, C. G., \& Danysz, W. (1997). Uncompetitive NMDA receptor antagonists attenuate NMDA-induced impairment of passive avoidance learning and LTP. Neuropharmacology, 36(7), 961-971. [DOI:10.1016/S0028-3908(97)00070-1]

Zajaczkowski, W., Hetman, M., Nikolaev, E., Quack, G., Danysz, W., \& Kaczmarek, L. (2000). Behavioural evaluation of long-term neurotoxic effects of NMDA receptor antagonists. Neurotoxicity Research, 1(4), 299-310. [PMID]

Zoladz, P. R., Campbell, A. M., Park, C. R., Schaefer, D., Danysz, W., \& Diamond, D. M. (2006). Enhancement of long-term spatial memory in adult rats by the noncompetitive NMDA receptor antagonists, memantine and neramexane. Pharmacology, Biochemistry, and Behavior, 85(2), 298-306. [PMID] 
This Page Intentionally Left Blank 